\title{
Response of Gastric Inhibitory Polypeptide (GIP) to Test Meal in Chronic Pancreatitis - Relationship to Endocrine and Exocrine Insufficiency
}

\author{
R. Ebert, W. Creutzfeldt, J. C. Brown*, H. Frerichs and R. Arnold \\ Division of Gastroenterology and Metabolism, Department of Medicine, University of Göttingen, Göttingen, Federal Republic of Germany
}

\begin{abstract}
Summary. Twenty-nine patients with chronic pancreatitis had a significantly greater IR-GIP response to a test meal than 15 controls. This increased response was not related to the degree of steatorrhoea or glucose intolerance. It was most marked in a group of patients with moderately impaired IRI release and medium steatorrhoea. From this is concluded that the IR-GIP response to a test meal is determined by at least two factors: 1 . feedback control via insulin secretion, 2. assimilation of fat. In chronic pancreatitis endocrine insufficiency may induce an exaggerated GIP response and severe exocrine insufficiency may prevent fat induced GIP release. Gastrin is not involved in the different GIP response in patients with chronic pancreatitis.
\end{abstract}

Key words: GIP, gastrin, insulin, incretin, chronic pancreatitis, test meal, malassimilation of fat.

It has been suggested that gastric inhibitory polypeptide (GIP) is one of the obvious incretin candidates [1, $3]$. Therefore, the GIP response to oral glucose or test meal has been investigated in human diabetics. Increased GIP response has been observed in all $[2,3]$ or a subgroup [4] of patients with maturity onset diabetes. Idiopathic human diabetes, especially of the maturity onset type, is a complex situation and its pathogenesis poorly understood. Diabetes in patients with chronic pancreatitis is a consequence of pancreatic damage. The degree of carbohydrate intolerance seems to be related to the loss of islet B-cells. It has been previously reported that a group of patients with chronic pancreatitis released significantly more

* Present address: Department of Physiology, The University of British Columbia, Vancouver, B. C., Canada V6T 1W5
GIP after a test meal [5] or an oral glucose load [14] than normal controls. Since the increased GIP response was not uniform, a group of 29 patients with chronic pancreatitis has now been analysed, with respect to the interdependence of the immunoreactive GIP (IR-GIP) response to a test meal to the degree of exocrine pancreatic insufficiency (maldigestion), the changes in serum immunoreactive insulin (IRI), immunoreactive gastrin (IRG) and glucose.

\section{Material and Methods}

\section{a. Subjects}

The investigations were performed in 15 controls and 29 patients with chronic pancreatitis. Informed consent was obtained from all subjects.

Controls. Fifteen healthy, normal volunteers (4 females, 11 males) with a mean age of 27 years (range 20 to 39 ) served as controls. These subjects were within $10 \%$ of their ideal body weight (mean weight $70.4 \mathrm{~kg}$ ) and had normal oral glucose tolerance.

Chronic Pancreatitis. Twenty-nine patients (9 females, 20 males) were investigated. Nineteen of these were identical with the cases of a previous communication [5]. The diagnosis of chronic pancreatitis was based on grossly abnormal pancreatic bicarbonate and enzyme responses after secretin and pancreozymin stimulation in all cases. Twenty-six of the 29 patients excreted more than $7.0 \mathrm{~g}$ fat in $24 \mathrm{~h}$. Twelve patients had radiologically ascertained pancreatic calcification. Eight patients had overt diabetes (only 3 of these had been treated with insulin), 14 were subclinical diabetics and 7 had normal oral glucose tolerance. The mean weight of the patients was $64.8 \pm 4.0 \mathrm{~kg}$, the average deviation from ideal body weight was $-7.0 \%$. 
Table 1. Integrated response ( $180 \mathrm{~min}$ ) of IR-GIP, IRG and glucose to a test meal in controls and patients with chronic pancreatitis, who were subdivided according to the degree of exocrine ( $3 a$ and $b$ ) and endocrine $(4 a, b$ and $c)$ insufficiency

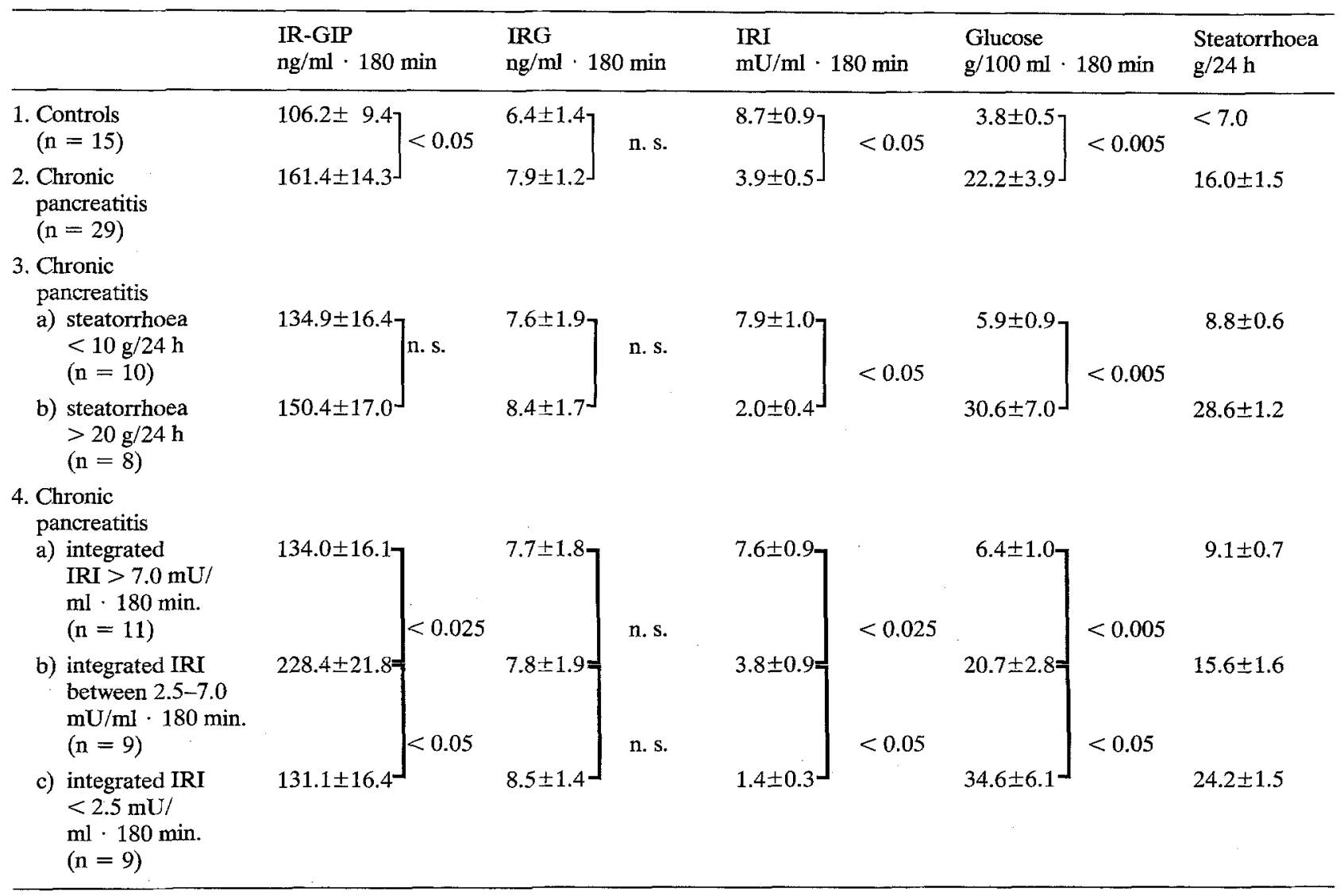

\section{b. Test Meal}

After an overnight fast, each subject was given a mixed test meal containing 1031 calories which was ingested within $10 \mathrm{~min}$ (for details see [5]).

\section{c. Laboratory Analyses}

Blood samples were drawn and laboratory analyses performed as described previously [5]. Serum glucose was measured by the glucose oxidase method, serum IRI determinded using human insulin as standard [6], serum IRG using antiserum 118/2/3 [7] and IR-GIP according to Kuzio et al. [8] with some modifications [5]. The GIP antiserum used (Van A/S No. 8) was raised in guinea pigs and the same as used in the original description of the assay [8]. Stool fat was estimated in three consecutive $24 \mathrm{~h}$ stool collections according to Van De Kamer [13] and the mean value given as steatorrhoea $(\mathrm{g} / 24 \mathrm{~h})$.

\section{d. Statistical Analysis}

All values are present as means \pm SEM. Results were analysed using standard statistical methods. Both, single values and integrated responses [9] were compared using Student's " $t$ " test for unpaired values.

\section{Results}

Serum levels of IR-GIP rose sharply after the test meal and remained elevated for at least $5 \mathrm{~h}$. Serum levels of IRG, IRI and glucose rose less sharply than the IR-GIP levels and started to decline after $3 \mathrm{~h}$ without reaching the fasting levels at the end of the test $(5 \mathrm{~h})$. The integrated responses of IR-GIP, IRG, IRI and glucose for the first $180 \mathrm{~min}$ are listed in Table 1. The IR-GIP and the glucose response of the patients with chronic pancreatitis was significantly larger than the response of the controls. The IRI response of the patients with chronic pancreatitis was significantly smaller and the IRG response not different from the controls.

Both, exocrine and endocrine function are usually impaired in chronic pancreatitis. Therefore the relationship between the degree of exocrine and endocrine insufficiency and the exaggerated IR-GIP response was analysed.

A comparison of the IR-GIP response of patients with chronic pancreatitis and mild maldigestion (steatorrhoea $<10 \mathrm{~g} / 24 \mathrm{~h}$ ) with the response of patients with severe maldigestion (steatorrhoea $>20$ $\mathrm{g} / 24 \mathrm{~h}$ ) revealed no significant difference (Table 1). Also the IRG response of these two gropus was not different. A significant difference was found in the IRI 
and glucose response: the patients with severe maldigestion had a much smaller IRI response and a much higher glucose response, suggesting a close correlation between exocrine and endocrine functional impairment.

Since an exaggerated IR-GIP response to glucose and test meal has been described in maturity-onset diabetes $[2,3,4]$ the patients with chronic pancreatitis were divided in three subgroups according to their integrated IRI response to the test meal as index for the B-cell insufficiency (Table 1). Three of the 9 patients with integrated IRI response $<2.5 \mathrm{mU} / \mathrm{ml} .180$ min had been treated with insulin for 1, 6 and 7 years respectively. Their IRI response was regarded as zero.

The integrated IRG response was not different in the three groups. The glucose response was highest in the group with the lowest and smallest in the group with the highest IRI response. The integrated IR-GIP response was not different between the patients with nearly normal IRI response and those with an IRI response below $2.5 \mathrm{mU} / \mathrm{ml} \cdot 180 \mathrm{~min}$, i. e. the overt diabetics who were mostly insulin dependent. However, a significantly larger integrated IR-GIP response was observed in the patients with chronic pancreatitis and moderately impaired IRI response (group $4 b$ of Table 1).

Figure 1 demonstrates the increase of the serum levels of IR-GIP, IRI, IRG and glucose in patients with chronic pancreatitis subdivided into three groups according to their IRI response to the test meal. The IR-GIP increase of the group with moderately impaired IRI response is significantly larger at times measured up to $4 \mathrm{~h}$, than the increase in patients with nearly normal and severely impaired IRI response (overt diabetics). The fasting IR-GIP levels are lowest in the group with nearly normal IRI response ( $272 \pm$ $68 \mathrm{pg} / \mathrm{ml}$ ) and highest in the group with lowest IRI response $(534 \pm 168 \mathrm{pg} / \mathrm{ml})$. However, due to the large variation this difference was not significant.

As demonstrated in Table 1 the degree of steatorrhoea is lowest in the group with nearly normal IRI response and highest in the patients with chronic pancreatitis and overt diabetes.

The average weight in the three groups of patients with chronic pancreatitis was as follows: patients with integrated IRI response $>7.0 \mathrm{mU} / \mathrm{ml} \cdot 180 \mathrm{~min}, 71.5$ $\mathrm{kg}$, patients with IRI response from $2.5-7.0,64.9 \mathrm{~kg}$ and patients with IRI response $<2.5,62.6 \mathrm{~kg}$. The average deviation from the ideal body weight was $+8 \%,-6.9 \%$ and $-12.3 \%$ respectively.

\section{Discussion}

The regulation of GIP release after ingestion of food is unknown. Any difference in the GIP release in certain
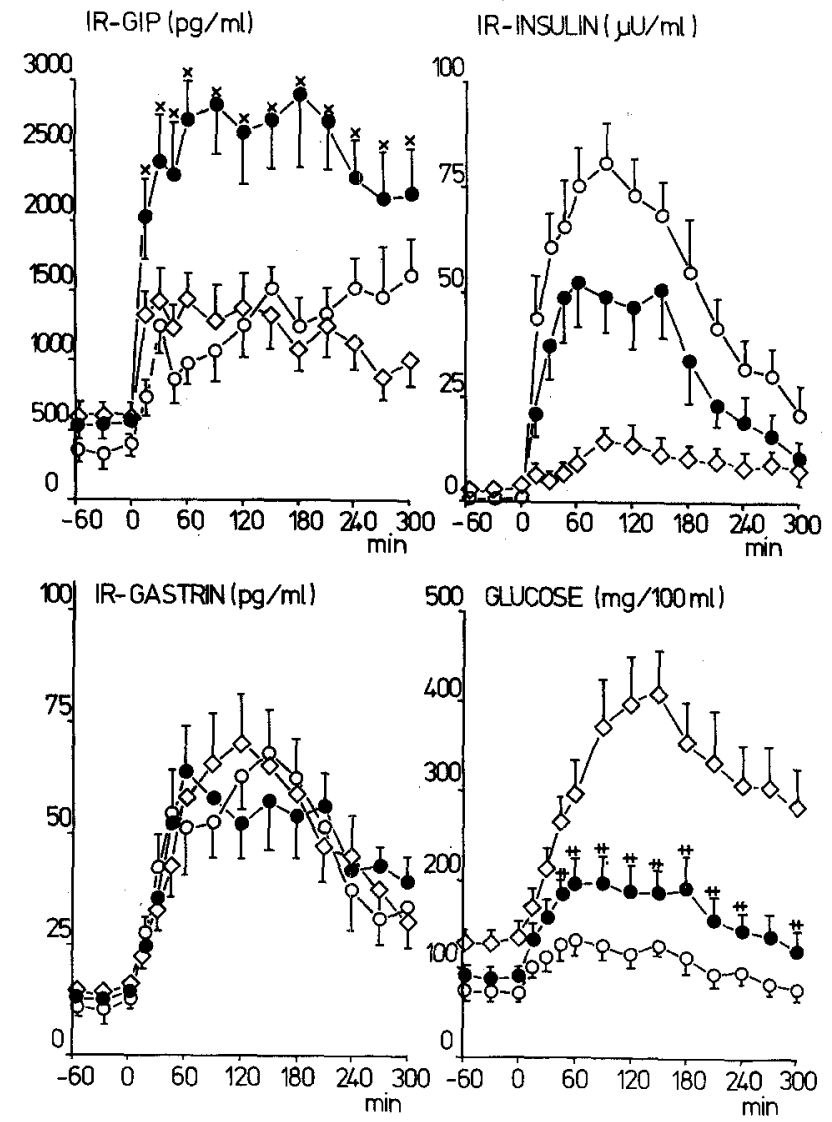

Fig. 1. Increase of serum levels of immunoreactive GIP, gastrin (IRG) and insulin (IRI) and of glucose in 29 patients with chronic pancreatitis. The patients are divided into three groups according to their IRI response to a test meal. Group $1\left(0 \_0\right)$ : integrated IRI $>7.0 \mathrm{mU} / \mathrm{ml} \cdot 180 \mathrm{~min}(\mathrm{n}=11)$. Group $2(\bullet-\bullet)$ : integrated IRI between $2.5-7.0 \mathrm{mU} / \mathrm{ml} \cdot 180 \mathrm{~min}(\mathrm{n}=9)$. Group 3 $\left(\diamond \_\diamond\right)$ : integrated IRI $<2.5 \mathrm{mU} / \mathrm{ml} \cdot 180 \mathrm{~min}(\mathrm{n}=9) . \mathrm{x}=$ significant difference $(p<0.01)$ between group 2 and 3 , respectively $1 .++=$ significant difference $(p<0.05)$ between group 2 and 1

diseases or under changed anatomical conditions [5] could help to elucidate this regulation.

Therefore, the increased release of IR-GIP to a mixed high caloric test meal in patients with chronic pancreatitis [5] has been analysed. In chronic pancreatitis exocrine and endocrine pancreatic function are impaired, usually in a parallel fashion and dependent on the stage of the disease. As demonstrated in Table 1 the test meal did not release more GIP in patients with a high degree of steatorrhoea if compared with patients with chronic pancreatitis and minor steatorrhoea (group 3 a and b). From this can be concluded that the malassimilation of fat cannot be the reason for the exaggerated IR-GIP response of patients with chronic pancreatitis. It has been found previously that in patients with malabsorption due to coeliac disease IR-GIP release is significantly less than in controls [5]. From this has been suggested that the GIP release may be dependent on the rate of nutrient absorption. In chronic pancreatitis only fat 
assimilation is significantly disturbed while glucose is absorbed normally. Serum IR-GIP increases more markedly and for longer after fat than after glucose ingestion $[3,11,12]$. Therefore, disturbed fat digestion in the case of gross exocrine insufficiency may reduce the IR-GIP response to a mixed meal.

It has been demonstrated that i v glucose does not release IR-GIP [3]. Therefore, the higher blood glucose levels after the test meal in patients with chronic pancreatitis do not explain as such the greater IR-GIP response. An attractive hypothesis is that insulin inhibits GIP release in the sense of a feedback control $[3,11]$. This would explain the elevated GIP levels described in patients with diabetes [2,3]. It also would explain the significantly greater IR-GIP response demonstrated here in patients with chronic pancreatitis. This greater response was significant for the whole group but most marked in the subgroup with moderately impaired IRI release while the subgroup with the severest impairment of IRI release revealed a smaller GIP response. This could be explained by the fact that this latter group had also the greatest exocrine pancreatic insufficiency. Due to the malassimilation of fat the GIP release was so small that the reduced feedback inhibition as a consequence of the B-cell insufficiency did not become apparent. The findings would support the idea that the release of IR-GIP to a test meal is dependent on at least two factors: the rate of absorption and the capacity of the B-cell for IRI secretion.

A further possibility may be discussed. It has been described that patients with chronic pancreatitis and severe insulinopenia have a relative hyperglucagonaemia [10]. This hypersecretion of glucagon could inhibit IR-GIP release because infusion of glucagon inhibits GIP response to a test meal in man (unpublished observations of the authours). Such a mechanism would explain why patients with severe insulinopenia (group $4 \mathrm{c}$ of Table 1) do not have an enhanced IR-GIP response to a meal. Further investigations are necessary to check this hypothesis. In the present experiments plasma glucagon levels have not been estimated. Theoretically, also other gastrointestinal hormones may interact with the release of GIP in response to a test meal. From the presented data it can only be concluded that the gastrin release is not involved in the regulation of IR-GIP release. The IRG response to the test meal was identical in all subgroups and not related to the differences in IR-GIP or IRI response.

Acknowledgements. This work was supported by the Deutsche Forschungsgemeinschaft, Bonn-Bad Godesberg, grant CR 20/7 (20/12) and grant
41/3208-Brown. The authors want to thank Mrs. K. Illmer, Miss E. Bothe and Mrs. B. Hillebrecht for their expert technical assistance.

\section{References}

1. Creutzfeld, W.: Insulin-releasing factors of the gastrointestinal mucosa (incretin). Gastroenterology 67, 748-750 (1974)

2. Crockett, S. E., Caterland, S., Falko, J., Mazzaferri, E. L.: Gastric inhibitory polypeptide (GIP): Response to variable doses of oral glucose in normal subjects and abnormal responses to oral glucose in patients with adult onset Diabetes mellitus (AODM). Diabetes 24, (Abstr.) 413 (1975)

3. Brown, J. C., Dryburgh, J. R., Ross, S. A., Dupré, J.: Identification and actions of gastric inhibitory polypeptide. Recent Progr. Hormone Res. 31, 487-532 (1975)

4. Bloom, S, R.: GIP in diabetes. Diabetologia 11, (Abstr.) 334 (1975)

5. Creutzfeldt, W., Ebert, R., Amold, R., Frerichs, H., Brown, J. C.: Gastric inhibitory polypeptide (GIP), gastrin and insulin: Response to test meal in coeliac disease and after duodenopancreatectomy. Diabetologia 12, 279-286 (1976)

6. Melani, F., Ditschuneit, H., Bartelt, K. M., Friedrich, H., Pfeiffer, E. F.: Úber die radioimmunologische Bestimmung von Insulin im Blut. Klin. Wschr. 43, 1000-1007 (1965)

7. Mayer, G., Arnold, R., Feurle, G., Fuchs, K., Ketterer, H., Track, N. S., Creutzfeldt, W.: Influence of feeding and sham feeding upon serum gastrin and gastric acid secretion in control subjects and duodenal ulcer patients. Scand. J. Gastroent. 9, 703-710 (1974)

8. Kuzio, M., Dryburgh, J. R., Malloy, K. M., Brown, J. C.: Radioimmunoassay for gastric inhibitory polypeptide. Gastroenterology 66, 357-364 (1974)

9. Stern, D. H., Walsh, J. H.: Gastrin release in postoperative ulcer patients: Evidence for release of duodenal gastrin. Gastroenterology 64, 363-369 (1973)

10. Kalk, W. J., Vinik, A. I., Bank, S., Buchanan, K. D., Keller, P., Jackson, W. P. U.: Glucagon responses to arginine in chronic pancreatitis. Diabetes 23, 257-263 (1974)

11. Cleator, I. G. M., Gourlay, R. H.: Release of immunoreactive gastric inhibitory polypeptide (IR-GIP) by oral ingestion of food substances. Amer. J. Surg. 130, 128-135 (1975)

12. Pederson, R. A., Schubert, H. E., Brown, J. C.: Gastric inhibitory polypeptide. Its physiologic release and insulinotropic action in the dog. Diabetes 24, 1050-1056 (1975)

13. van de Kamer, J. H., ten Bokkel Huinink, H., Weijers, H. A.: Rapid method for the determination of fat in feces. J. biol. Chem. 177, 347-355 (1959)

14. Botha, J. L., Vinik, A. I., Brown, J. C.: Gastric inhibitory polypeptide (GIP) in chronic pancreatitis. J. clin. Endocr. 42, $791-797$ (1976)

Received: July 2, 1976, and in revised form: August 3, 1976

Prof. Dr. med. W. Creutzfeldt

Medizinische Universitäts-Klinik

Humboldtallee 1

D-3400 Göttingen

Federal Republic of Germany 